\title{
Barriers to participation in physical activity and exercise among middle-aged and elderly individuals
}

\author{
Maria Justine ${ }^{1}$, PhD, PT, Azliyana $\underline{\text { Azizan }}^{1}$, BPT, Vaharli Hassan ${ }^{2}$, BPT, Zoolfaiz Salleh ${ }^{1}$, BPT, \\ Haidzir Manaf ${ }^{1}$, BSc, PT
}

\begin{abstract}
INTRODUCTION Although the benefits of physical activity and exercise are widely acknowledged, many middleaged and elderly individuals remain sedentary. This cross-sectional study aimed to identify the external and internal barriers to physical activity and exercise participation among middle-aged and elderly individuals, as well as identify any differences in these barriers between the two groups.

METHODS Recruited individuals were categorised into either the middle-aged (age 45-59 years, $n=60$ ) or elderly (age $\geq 60$ years, $n=60$ ) group. Data on demographics, anthropometry, as well as external and internal barriers to participation in physical activity and exercise were collected.

RESULTS Analysis showed no significant differences in the total scores of all internal barriers between the two groups $(p>0.05)$. The total scores for most external barriers between the two groups also showed no significant differences $(p>0.05)$; only 'cost' $(p=0.045)$ and 'exercise interferes with social/family activities' $(p=0.011)$ showed significant differences. The most common external barriers among the middle-aged and elderly respondents were 'not enough time' ( $46.7 \%$ vs. $48.4 \%)$, 'no one to exercise with' $(40.0 \%$ vs. $28.3 \%)$ and 'lack of facilities' (33.4\% vs. $35.0 \%)$. The most common internal barriers for middle-aged respondents were 'too tired' (48.3\%), 'already active enough' (38.3\%), 'do not know how to do it' (36.7\%) and 'too lazy' (36.7\%), while those for elderly respondents were 'too tired' (51.7\%), 'lack of motivation' (38.4\%) and 'already active enough' (38.4\%).

CONCLUSION Middle-aged and elderly respondents presented with similar external and internal barriers to physical activity and exercise participation. These factors should be taken into account when healthcare policies are being designed and when interventions such as the provision of facilities to promote physical activity and exercise among older people are being considered.
\end{abstract}

Keywords: barrier, elderly, exercise, middle-aged, physical activity

\section{INTRODUCTION}

Regular participation in physical activity and exercise has been shown to be beneficial for various physiological systems, and in improving the quality of life of adults. ${ }^{(1-3)}$ It is recommended that the adult population performs an average of 30 mins of moderate-intensity activities on most days of the week in order to maintain health and prevent chronic illnesses. ${ }^{(4)}$ For senior citizens, it is recommended that individuals perform moderate physical activity at an average of 3-6 metabolic equivalents of task (METs; which is equivalent to brisk walking at a speed of 3-4 miles/hr). ${ }^{(5)}$ Despite such recommendations, many adults, especially middle-aged and elderly individuals, prefer to remain sedentary. Research conducted by the Center for Disease Control and Prevention, United States, in 1996 revealed that more than $60 \%$ of the adult population did not participate in physical activity and $25 \%$ was sedentary. ${ }^{(6)}$ Similarly, a study from Hong Kong reported that one-fifth of the registered deaths among people aged $\geq 35$ years in the country were associated with low levels of physical activity. ${ }^{(7)}$

Many studies have indicated that an awareness of the importance of physical activity could be attributed to external and internal barriers. ${ }^{(8-11)}$ External barriers refer to factors beyond an individual's control, whereas internal barriers are factors determined by an individual's personal decision. ${ }^{(12)}$ The Health Belief Model (HBM) seems to be the most commonly used tool to identify these barriers, and to explain and predict health behaviours in relation to health promotion. ${ }^{(13)}$ It focuses on how an individual's perception of risks and benefits can influence the likelihood of behaviour change for the protection of his or her health. ${ }^{(14)}$ In the present study, we used HBM to understand and predict how respondents would behave with regard to participation in physical activity and exercise. The lack of involvement in physical activity has been linked to several domains including health status (e.g. chronic health problem and pain), ${ }^{(15)}$ environmental factors (e.g. accessibility to exercise facilities $^{(3,16,17)}$ and neighbourhood safety $\left.{ }^{(18)}\right)$, psychological issues (e.g. self-commitment $\left.{ }^{(9,19)}\right)$, negative perception of exercise outcome ${ }^{(3,20)}$ and demographic background (e.g education level ${ }^{(19)}$ and age group $\left.{ }^{(21)}\right)$. Conn et $\mathrm{al}^{(22)}$ indicated that age-related behavioural changes may influence exercise self-efficacy and expectation for exercise. They also found that elderly individuals tended to have lower self-efficacy because they believed that their physical ability had deteriorated with age.(22)

\footnotetext{
${ }^{1}$ Physiotherapy Department, Faculty of Health Sciences, Universiti Teknologi MARA, Selangor, ${ }^{2}$ Masterskill Global College, Kota Kinabalu Campus, Sabah, Malaysia Correspondence: Dr Maria Justine, Senior Lecturer, Physiotherapy Department, Faculty of Health Sciences, Universiti Teknologi MARA, Puncak Alam Campus, 42300, Puncak Alam, Selangor, Malaysia. mar_physio@yahoo.com
} 
Currently, Malaysia faces the challenge of an increasingly ageing population. The percentage of elderly Malaysians has been projected to increase from $6.3 \%$ in 2000 to $12.0 \%$ (or 4.9 million individuals) by $2030 .{ }^{(23)}$ It is therefore crucial that healthcare practitioners in Malaysia understand the challenges and issues pertinent to an ageing population, in order to make possible the formulation of appropriate exercise strategies for elderly individuals and the facilitation of the effective management of these strategies. The purpose of the present study was to identify the external and internal barriers to participation in physical activity and exercise among middleaged (age 45-59 years) and elderly (age $\geq 60$ years) individuals in Malaysia, as well as identify any differences in the barriers between the two groups.

\section{METHODS}

This was a cross-sectional study conducted between November 2010 and April 2011. This study recruited a convenience sample from a selected village in Kuang, Selangor, Malaysia. The village was chosen as it had basic facilities such as a community health clinic, a post office, a community hall and schools. Furthermore, exchanges with the village head revealed that there were nearly 300 elderly individuals residing in the village. The study protocol was approved by the Research Ethic Committee of the Faculty of Health Sciences, Universiti Teknologi MARA (UiTM), Malaysia.

The criteria for inclusion in the study were an age of $\geq 45$ years, no cognitive impairment (based on the Mini Mental State Examination $\left.{ }^{(24)}\right)$, independence in activities of daily living and residence in the selected village. The exclusion criteria adopted were unstable medical condition at the time of study and lack of interest. All respondents gave their consent and completed the study questionnaire that covered demographic information, health status, and involvement in physical activity and exercises. Anthropometric measurements such as weight and height were taken using a portable stadiometer (Seca 708 1314004; Vokel \& Halke GmbH \& Co, Hamburg, Germany). The Barriers in Physical Activity and Exercise Participation (BPEP) questionnaire was used to identify the major external and internal barriers among respondents. ${ }^{(25)}$ The original questionnaire, consisting of 45 questions, was developed based on HBM because its scale was shown to have good internal consistency, with a reported Cronbach's alpha coefficient of $>0.60 .{ }^{(26)}$ Item responses in the BPEP questionnaire were structured and evaluated in a Likert scale format, i.e. scales used to interpret responses to statements were given scores ranging from 5 (strongly agree) to 1 (strongly disagree). Lower scores indicated negative belief, while higher scores indicated positive belief.

The original English version of the BPEP questionnaire was translated into Bahasa Malaysia according to international guidelines. ${ }^{(25)}$ The final Bahasa Malaysia version of the questionnaire consisted of 22 items on the various barrier
Table I. Demographic and anthropometric characteristics of the study population $(n=120)$.

\begin{tabular}{|c|c|c|}
\hline \multirow[t]{2}{*}{ Variable } & \multicolumn{2}{|c|}{ No. of respondents (\%) } \\
\hline & $\begin{array}{l}\text { Middle-aged } \\
\quad(n=60)\end{array}$ & $\begin{array}{l}\text { Elderly } \\
(n=60)\end{array}$ \\
\hline Age* (yrs) $^{*}$ & $51.70 \pm 4.15$ & $67.82 \pm 6.62$ \\
\hline $\begin{array}{l}\text { Gender } \\
\text { Male } \\
\text { Female }\end{array}$ & $\begin{array}{l}19(31.7) \\
41(68.3)\end{array}$ & $\begin{array}{l}23(38.3) \\
37(61.7)\end{array}$ \\
\hline $\begin{array}{l}\text { Marital status } \\
\text { Married } \\
\text { Divorced or separated } \\
\text { Widowed }\end{array}$ & $\begin{array}{c}56(93.3) \\
1(1.7) \\
3(5.0)\end{array}$ & $\begin{array}{c}37(61.7) \\
1(1.7) \\
22(36.7)\end{array}$ \\
\hline $\begin{array}{l}\text { Education level } \\
\text { None } \\
\text { Primary } \\
\text { Secondary } \\
\text { Tertiary }\end{array}$ & $\begin{array}{r}6(10.0) \\
17(28.3) \\
29(48.3) \\
8(13.3)\end{array}$ & $\begin{aligned} 9 & (15.0) \\
30 & (50.0) \\
16 & (26.7) \\
5 & (8.3)\end{aligned}$ \\
\hline $\begin{array}{l}\text { Occupation } \\
\text { Unemployed } \\
\text { Housewife } \\
\text { Non-technical } \\
\text { Technical } \\
\text { Retired } \\
\text { Other }\end{array}$ & $\begin{aligned} 1 & (1.7) \\
36 & (60.0) \\
12 & (20.0) \\
3 & (5.0) \\
1 & (1.7) \\
7 & (11.7)\end{aligned}$ & $\begin{aligned} 9 & (15.0) \\
26 & (43.3) \\
4 & (6.7) \\
5 & (8.3) \\
13 & (21.7) \\
3 & (5.0)\end{aligned}$ \\
\hline $\begin{array}{l}\text { Participation in exercise } \\
\text { Yes } \\
\text { No }\end{array}$ & $\begin{array}{l}28(46.7) \\
32(53.3)\end{array}$ & $\begin{array}{l}19(31.7) \\
41(68.3)\end{array}$ \\
\hline $\begin{array}{l}\text { Anthropometric } \\
\text { measurements } \\
\text { Body weight }(\mathrm{kg}) \\
\text { Height }(\mathrm{m}) \\
\text { Body mass index }\left(\mathrm{kg} / \mathrm{m}^{2}\right)\end{array}$ & $\begin{aligned} 65.93 & \pm 15.79 \\
1.60 & \pm 0.10 \\
25.39 & \pm 5.18\end{aligned}$ & $\begin{aligned} 63.13 & \pm 11.71 \\
1.62 & \pm 0.07 \\
23.87 & \pm 3.68\end{aligned}$ \\
\hline
\end{tabular}

${ }^{*}$ Data is presented as mean \pm standard deviation.

domains. The reliability of the Bahasa Malaysia version of the questionnaire was demonstrated using internal consistency and test-retest analyses, in which 79 healthy adults (aged 45-65 years) not involved in the actual study were asked to complete the questionnaire twice within an interval of two weeks. Each question was analysed separately. The Bahasa Malaysia BPEP questionnaire was found to have excellent internal consistency (Cronbach's alpha $=0.92$ ) and good testretest correlations (range 0.74-0.95). There were no significant differences in the total scores of the various barriers between the first and second tests.

Data was analysed using the Statistical Package for the Social Sciences for Windows version 16.0 (SPSS Inc, Chicago, IL, USA). Analysis consisted of descriptive statistics to express the results in terms of frequency, percentage and mean \pm standard deviation. Independent $t$-test was used to measure the differences in the means of each item, and the total scores for the external and internal barriers. The significance level was set at 0.05. The assumption of equality of variance and normality was determined using Levene's and Shapiro-Wilk tests, respectively.

\section{RESULTS}

A total of 120 respondents (60 middle-aged, 60 elderly) participated in the study. Table I shows the demographic and 


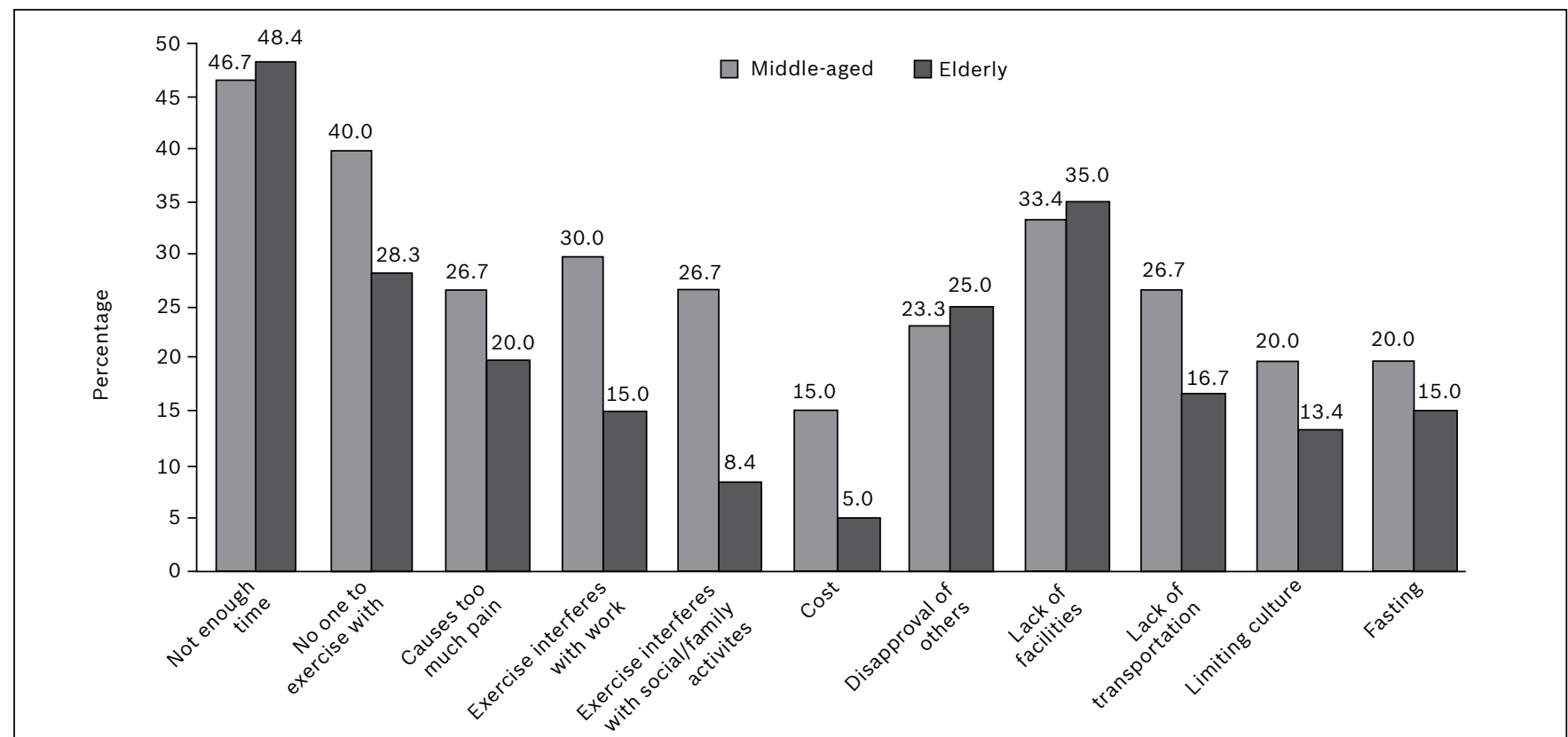

Fig. 1 Graph shows the external barriers to participation in physical activity among middle-aged $(n=60)$ and elderly $(n=60)$ respondents.

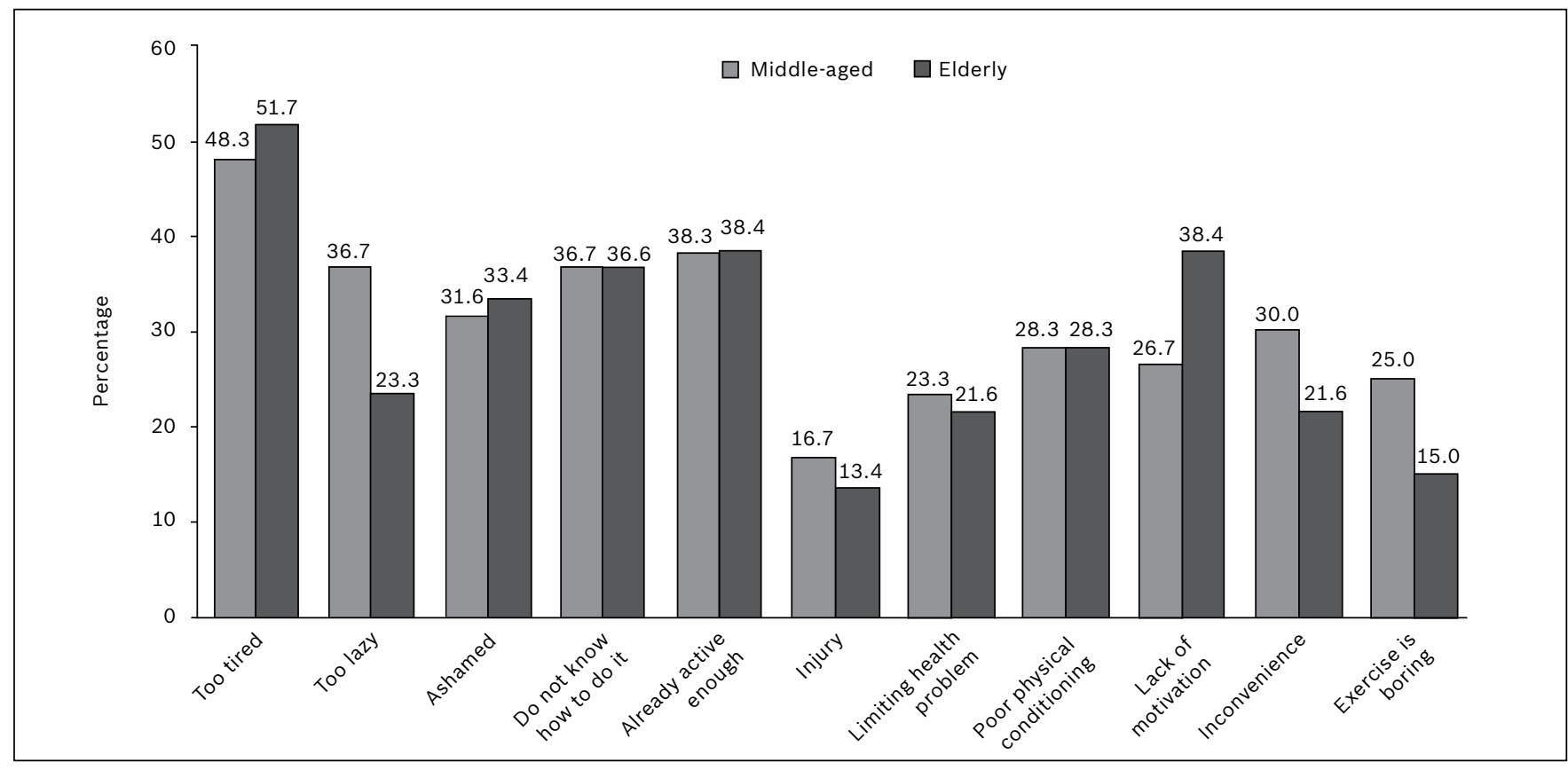

Fig. 2 Graph shows internal barriers to participation in physical activity among middle-aged $(n=60)$ and elderly $(n=60)$ respondents.

anthropometric characteristics of the respondents. The mean age of the middle-aged respondents was $51.70 \pm 4.15$ years, while that of the elderly respondents was $67.82 \pm 6.62$ years. The majority of both the middle-aged and elderly respondents were women $(68.3 \%$ and $61.7 \%$, respectively). All respondents were Malay. This was not unexpected since the majority of the residents in the Kuang district was of Malay ethnicity. A majority of the middle-aged (93.3\%) and elderly (61.7\%) respondents were married. Most middle-aged (48.3\%) respondents had a secondary school education, while a majority of the elderly respondents $(50.0 \%)$ had a primary school education. Most middle-aged (60.0\%) and elderly $(43.3 \%)$ respondents were housewives - a finding reflecting the fact that the majority of respondents in both groups were women. With regard to participation in exercise, only $46.7 \%$ of the middle-aged respondents and $31.7 \%$ of the elderly respondents participated in regular exercise at the time of study. The mean body mass index of middle-aged respondents was $25.39 \pm 5.18 \mathrm{~kg} / \mathrm{m}^{2}$, while that of the elderly respondents was $23.87 \pm 3.68 \mathrm{~kg} / \mathrm{m}^{2}$.

Fig. 1 shows the breakdown of responses regarding external barriers to participation in physical activity and exercise among the middle-aged and elderly respondents. Combining the 'agree' and 'strongly agree' response categories, the three most common external barriers to participation in physical activity and exercise among middle-aged respondents were found to be 'not enough time' $(46.7 \%)$, 'no one to exercise with' (40.0\%) and 'lack of facilities' (33.4\%). Meanwhile, 
Table II. Comparison of the means of external and internal barriers between middle-aged and elderly respondents $(n=120)$.

\begin{tabular}{|c|c|c|c|}
\hline \multirow[t]{2}{*}{ Barrier } & \multicolumn{2}{|c|}{ Mean \pm SD } & \multirow[t]{2}{*}{ p-value } \\
\hline & $\begin{array}{l}\text { Middle-aged respondents } \\
\qquad(n=60)\end{array}$ & $\begin{array}{l}\text { Elderly respondents } \\
\qquad(n=60)\end{array}$ & \\
\hline \multicolumn{4}{|l|}{ External } \\
\hline Not enough time & $3.12 \pm 1.24$ & $3.32 \pm 1.23$ & 0.376 \\
\hline No one to exercise with & $3.03 \pm 1.12$ & $2.80 \pm 1.18$ & 0.268 \\
\hline Causes too much pain & $2.90 \pm 1.10$ & $2.57 \pm 1.14$ & 0.106 \\
\hline Exercise interferes with work & $2.77 \pm 1.02$ & $2.47 \pm 0.99$ & 0.103 \\
\hline $\begin{array}{l}\text { Exercise interferes with } \\
\text { social/family activities }\end{array}$ & $2.70 \pm 1.01$ & $2.25 \pm 0.90$ & $0.011^{*}$ \\
\hline Cost & $2.60 \pm 1.03$ & $2.25 \pm 0.86$ & $0.045^{*}$ \\
\hline Disapproval of others & $2.43 \pm 1.27$ & $2.17 \pm 1.11$ & 0.222 \\
\hline Lack of facilities & $2.92 \pm 1.08$ & $2.93 \pm 1.06$ & 0.932 \\
\hline Lack of transportation & $2.67 \pm 1.12$ & $2.55 \pm 1.02$ & 0.550 \\
\hline Limiting culture & $2.72 \pm 1.03$ & $2.52 \pm 1.0$ & 0.282 \\
\hline Fasting & $2.68 \pm 0.91$ & $2.50 \pm 0.81$ & 0.247 \\
\hline Sum of scores & $30.53 \pm 6.89$ & $28.32 \pm 5.90$ & 0.061 \\
\hline \multicolumn{4}{|l|}{ Internal } \\
\hline Too tired & $3.12 \pm 3.12$ & $3.27 \pm 1.22$ & 0.507 \\
\hline Too lazy & $2.92 \pm 2.92$ & $2.83 \pm 1.20$ & 0.720 \\
\hline Ashamed & $2.82 \pm 2.82$ & $2.92 \pm 1.11$ & 0.613 \\
\hline Do not know how to do it & $2.92 \pm 2.92$ & $2.95 \pm 1.16$ & 0.873 \\
\hline Already active enough & $2.95 \pm 2.95$ & $3.05 \pm 1.27$ & 0.667 \\
\hline Injury & $2.52 \pm 2.52$ & $2.28 \pm 0.99$ & 0.228 \\
\hline Limiting health problem & $2.67 \pm 2.67$ & $2.53 \pm 1.20$ & 0.537 \\
\hline Poor physical conditioning & $2.63 \pm 2.63$ & $2.60 \pm 1.28$ & 0.879 \\
\hline Lack of motivation & $2.80 \pm 2.80$ & $3.00 \pm 1.18$ & 0.323 \\
\hline Inconvenience & $2.85 \pm 2.85$ & $2.77 \pm 0.89$ & 0.622 \\
\hline Exercise is boring & $2.70 \pm 2.70$ & $2.52 \pm 0.95$ & 0.325 \\
\hline Sum of scores & $30.88 \pm 7.58$ & $30.72 \pm 6.63$ & 0.898 \\
\hline
\end{tabular}

${ }^{*} \mathrm{p}<0.05$. SD: standard deviation

'not enough time' (48.4\%), 'lack of facilities' (35.0\%), and 'no one to exercise with' (28.3\%) were also found to be the three most common barriers to participation in physical activity and exercise among elderly respondents. The breakdown of the responses regarding internal barriers to participation in physical activity and exercise are shown in Fig. 2. The most common internal barriers among middle-aged respondents were 'too tired' (48.3\%), 'already active enough' (38.3\%), 'do not know how to do it' (36.7\%) and 'too lazy' (36.7\%). The most common internal barriers among elderly respondents were 'too tired' (51.7\%), 'lack of motivation' (38.4\%) and 'already active enough' (38.4\%).

Table II shows the results of the independent $t$-test comparing the means of the external and internal barriers between middle-aged and elderly respondents. There was no significant difference between the middle-aged and elderly respondents for most of the external, and all the internal, barriers tested. However, significant differences were found between the middle-aged and elderly respondents for the following external barriers: 'cost' $(p=0.045)$ and 'exercise interferes with social/family activities' $(p=0.011)$.

\section{DISCUSSION}

To gain a better understanding of the issues associated with the physical inactivity and low levels of exercise generally observed in the adult population, this study aimed to identify the external and internal barriers to participation in physical activity and exercise among the middle-aged and elderly individuals in a community. We also sought to establish whether differences existed between the two groups with respect to these barriers. The results of our study show that there were no significant differences in the total scores of the external and internal barriers between the two age groups. However, significant differences between the middle-aged and elderly respondents were found for the following individual external barrier items: 'cost' $(p=0.045)$ and 'exercise interferes with social/ family activities' ( $p=0.011$ ). In 2006, a survey conducted by Schuler et al on the barriers and motivations to exercise among older African-American and European-American women highlighted significant differences between these two populations with respect to the perception that exercise is too expensive. ${ }^{(18)}$ However, as the number of participants from the two ethnic groups was small in the survey (1 AfricanAmerican, 5 European-Americans), the difference found was not statistically significant.

It is interesting to note that the middle-aged respondents in our study had higher means for both external and internal barriers (30.53 and 30.88, respectively) when compared to the elderly respondents. This could be because the middle-aged respondents believed that their routines already provided them with the required exercise. Routine activities cited included charity work and social interaction such as 'Marhaban', which is a religious activity that involves house-to-house carolling for the purpose of reciting prayers and praises. ${ }^{(27)}$ These activities were still widely practised in the village chosen for our study. 
In our study, 'not having enough time' was found to be a major external barrier for participation in physical activity and exercise in both age groups. This may be explained in part by the general opinion harboured by the participants that exercise is time-consuming. This finding was also observed in Pham et al's study, ${ }^{(19)}$ which found that the three most crucial barriers among Chinese women aged 30-59 years were insufficient time, inadequate skill and resource, and lack of support from family or friends. In another recent study, Schutzer and Graves similarly reported lack of time as an important barrier in 17 inactive older adults aged 50-75 years, who rated exercise as the lowest priority in their life. ${ }^{(28)}$ These findings are indicative of the generally low importance given to exercise by elderly populations; some responses even suggested that they view exercise to be a waste of time. Thus, there may be a need for healthcare providers to organise campaigns and educational programmes that promote exercise in individuals from this age group, so that participation in exercise and long-term adherence are encouraged. Tips on how to achieve effective time management would also help this group of individuals reduce overlaps with sedentary activities and promote participation in exercise.

According to a review by Schutzer and Graves, ${ }^{(28)}$ older adults who were inactive were found to be living a considerable distance away from recreational centres, sidewalks, parks or other fitness facilities that could motivate engagement in exercise such as walking. Lack of facilities was also found to be an important barrier to participation in physical activity and exercise in our study. As our survey was conducted in a small village from an underdeveloped area, fitness facilities were not available around the study location. Governments play an important role in providing subsidies or funds for the development of healthcare facilities (e.g. wellness centres and walking tracks) that will afford greater opportunities for lifestyle modification.

Both groups of respondents in our study indicated that having 'no one to exercise with' was one of the barriers to active participation in exercise and physical activity. Generally, the elderly prefer to spend their time at home (e.g. playing with grandchildren) rather than participate in physical activity and exercise with friends of the same age. Both middle-aged and elderly individuals, especially women, usually prefer to perform routine activities such as gardening and household chores. Previous reviews have shown that adult populations have poor awareness of the beneficial effects of exercise in disease prevention due to a lack of knowledge and low education levels. ${ }^{(29)}$ Given the higher levels of inactivity observed among our respondents and the fact that physical inactivity could lead to serious health problems, proper guidance should be provided to encourage these individuals to set their own exercise goals. Enjoyable and convenient exercise programmes should also be designed to appeal to more inactive people and encourage them to adhere to recommended exercise regimes.
Where internal barriers were concerned, we found tiredness to be an important impediment to exercise participation in both groups. This finding is consistent with that of studies by Sallinen et al and Cooper et al. ${ }^{(30,31)}$ Sallinen et al's study, which evaluated the barriers to physical exercise in elderly individuals who were obese, found that severely obese older adults (mean age 77.3 years) perceived 'feeling tired' as a common barrier, leading to a higher risk of physical inactivity. Reichert et al also reported that the feeling of being too tired was associated with physical inactivity among adults aged 20 years and above. ${ }^{(21)}$

According to Chao et al, ${ }^{(32)}$ self-motivation determines participation in structured physical activity. They pointed out that the motivation to exercise may be altered over time, in association with the individual's commitment. A study on younger women by Andajani-Sutjahjo et $\mathrm{al}^{(33)}$ found that the most common barriers to physical activity in this group were also associated with a lack of motivation, followed by time constraints and cost. Similarly, lack of motivation was determined to be the most important barrier to physical activity among young undergraduates from a Turkish university in a study by Daskapan et al. ${ }^{(34)}$ In the present study, we found similar results, with lack of motivation as one of the main barriers indicated by the elderly respondents to have contributed to inactivity.

One major critique of the present study is the fact that the middle-aged and elderly respondents in our study may not be entirely comparable, as the two groups have differing levels of physical activity and health statuses due to age-related physiological changes. The elderly respondents may have progressive physiological changes and chronic diseases that are common for their age. Also, as the present study only included respondents of Malay ethnicity, further research using stratified sampling on larger sample sizes with respondents from various cultural backgrounds is warranted so that findings can be generalised to the local ageing population in Malaysia. Future research should also focus on whether the provision of interventions such as rehabilitation training, infrastructure and community services are beneficial to the middle-aged and elderly members of the community.

In conclusion, the present study adds to the existing literature on the barriers to participation in physical activity and exercise among middle-aged and elderly individuals in the community. We found that the middle-aged and elderly respondents in our study both presented with similar external and internal barriers to physical activity and exercise participation. Such information is vital for the formulation of guidelines that aim to help middle-aged and elderly individuals overcome barriers to participation in physical activity and exercise, as well as for the creation of structured strategies to improve adherence to exercise. It is suggested that both the government sector and non-governmental organisations participate in promoting healthy lifestyles among middle-aged and elderly individuals, 
so as to improve awareness and promote preventive self-care and risk-reduction.

\section{ACKNOWLEDGEMENTS}

This project was made possible by grants from the Research Management Institute (600-RMI/DANA 5/3/RIF [511/2012]), Universiti Teknologi MARA, Selangor, Malaysia, via the Research Intensive Faculty/Excellence Fund. The authors are grateful to the participants from the community of Kampung Damai Kuang, Selangor, Malaysia, for their cooperation and support.

\section{REFERENCES}

1. King KA, Krista M, Bernard AL, Vidourek RA. Does involvement in healthy eating among university students differ based on exercise status and reasons for exercise? Californian J Health Promot 2007; 5:106-19.

2. Lim K, Taylor L. Factors associated with physical activity among older people-a population-based study. Prev Med 2005; 40:33-40.

3. Forkan R, Pumper B, Smyth N, et al. Exercise adherence following physical therapy intervention in older adults with impaired balance. Phys Ther 2006; 86:401-10.

4. Nelson ME, Rejeski WJ, Blair SN, et al. Physical activity and public health in older adults: recommendation from the American College of Sports Medicine and the American Heart Association. Med Sci Sports Exerc 2007; 39:1435-45.

5. Pate RR, Pratt M, Blair SN, et al. Physical activity and public health. A recommendation from the Centers for Disease Control and Prevention and the American College of Sports Medicine. JAMA 1995; 273:402-7.

6. U.S. Department of Health and Human Services. Physical activity and health; A Report of the Surgeon General. Atlanta, GA: U.S. Department of Health and Human Services, Centers for Disease Control and Prevention, National Center for Chronic Disease Prevention and Health Promotion 1996 [online]. Available at: www.cdc.gov/nccdphp/sgr/pdf/chap5.pdf. Accessed March 12, 2010.

7. Lam TH, Ho SY, Hedley AJ, Mak KH, Leung GM. Leisure time physical activity and mortality in Hong Kong: case-control study of all adult deaths in 1998. Ann Epidemiol 2004; 14:391-8.

8. Stutts WC. Physical activity determinants in adults. Perceived benefits, barriers, and self-efficacy. AAOHN J 2002; 50:499-507.

9. Kamwendo K, Askendom M, Wahlgren C. Physical activity in the life of the patient with rheumatoid arthritis. Physiother Res Int 1999; 4:278-92.

10. Larkin JM. Psychosocial determinants of exercise in people 65 and older: Recruitment and population campaign strategies. Dissertation Abstracts International Section A: Human and Social Science 2005; 65:3712.

11. Netz Y, Wu MJ, Becker BJ, Tenenbaum G. Physical activity and psychological well-being in advanced age: a meta-analysis of intervention studies. Psychol Aging 2005; 20:272-84.

12. Korkiakangas EE, Alahuhta AA, Laitinen JH. Barriers to regular exercise among adults at high risk or diagnosed with type 2 diabetes: a systematic review. Health Promot Int 2009; 24:416-27.

13. Hanson JA, Benedict JA. Use of the Health Belief Model to examine older adults' food-handling behaviors. J Nutr Educ Behav 2002; 34 Suppl 1:S25-30.

14. van de Mortel TF. Development of a questionnaire to assess health care students' hand hygiene knowledge, beliefs and practices. Aust J Adv Nurs 2009; 26:9-16
15. Ziebland S, Thorogood M, Yudkin P, Jones L, Coulter A. Lack of willpower or lack of wherewithal? "Internal" and "external" barriers to changing diet and exercise in a three year follow-up of participants in a health check. Soc Sci Med 1998; 46:461-5.

16. Cohen-Mansfield J, Marx MS, Biddison JR, Guralnik JM. Socioenvironmental exercise preferences among older adults. Prev Med 2004; 38:804-11.

17. Sit CHP, Kerr JH, Wong ITF. Motives for and barriers to physical activity participation in middle-aged Chinese women. Psychol Sport Exerc 2008; 9:266-83.

18. Schuler PB, Roy JLP, Vinci D, Philipp SF, Cohen SJ. Barriers and motivations to exercise in older African American and European American women. Californian J Health Promot 2006; 4:128-34.

19. Pham KL, Harrison GG, Kagawa-Singer M. Perceptions of diet and physical activity among California Hmong adults and youths. Prev Chronic Dis 2007; 4:A93.

20. Dutton GR, Johnson J, Whitehead D, Bodenlos JS, Brantley PJ. Barriers to physical activity among predominantly low-income African-American patients with type 2 diabetes. Diabetes Care 2005; 28:1209-10.

21. Reichert FF, Barros AJD, Domingues MR, Hallal PC. The role of perceived personal barriers to engagement in leisure-time physical activity. Am J Public Health 2007; 97:515-19.

22. Conn VS, Burks KJ, Pomeroy SH, Ulbrich SL, Cochran JE. Older women and exercise: explanatory concepts. Womens Health Issues 2003; 13:158-66.

23. Rabieyah M, Hajar T. Socio-economic characteristics of the elderly in Malaysia. In: 21st Population Census Conference 19-21 Novermber 2003 Kyoto, Japan. Analysis of the 2000 round of censuses [online]. Available at: http://www.ancsdaap.org/cencon2003/Papers/Malaysia/Malaysia.pdf. Accessed March 14, 2010.

24. Folstein MF, Folstein SE, McHugh PR. "Mini-mental state". A Practical method for grading the cognitive state of patients for the clinician. J Psychiatr Res 1975; 12:189-98.

25. Karimlou M, Zayeri F, Salehi M. Psychometric properties of the Persian version of the World Health Organization's quality of life questionnaire (WHOQOL-100). Arch Iran Med 2011; 14:281-7.

26. Setbon $M$, Raude J. Factors in vaccination intention against the pandemic influenza A/H1N1. Eur J Public Health 2010; 20:490-4.

27. Mehta KK. The impact of religious beliefs and practices on aging: A crosscultural comparison. J Aging Stud 1997; 11:101-14.

28. Schutzer KA, Graves BS. Barriers and motivations to exercise in older adults. Prev Med 2004; 39:1056-61.

29. Buman MP, Yasova D, Giacobbi PR. Descriptive and narrative reports of barriers and motivators to physical activity in sedentary older adults. Psychol Sport Exerc 2010; 11:223-30.

30. Sallinen J, Leinonen R, Hirvensalo M, et al. Perceived constraints on physical exercise among obese and non-obese older people. Prev Med 2009; 49:506-10.

31. Cooper KM, Bilbrew D, Dubbert PM, Kerr K, Kirchner K. Health barriers to walking for exercise in elderly primary care. Geriatr Nurs 2001; 22:258-62.

32. Chao D, Foy CG, Farmer D. Exercise adherence among older adults: challenges and strategies. Control Clin Trials 2000; 21 Suppl 5:212S-17S

33. Andajani-Sutjahjo S, Ball K, Warren N, Inglis V, Crawford D. Perceived personal, social and environmental barriers to weight maintenance among young women: A community survey. Int J Behav Nutr Phys Act 2004; 1:15.

34. Daskapan A, Tuzun EH, Eker L. Perceived barriers to physical activity in university students. J Sports Sci Med 2006; 5:615-20. 